\title{
THE 1992 ARCHAEOLOGICAL SURVEYS ON ESMERALDA STATION, GULF OF CARPENTARIA: PRELIMINARY RESULTS
}

\author{
PAUL GORECKI, MIRANDA GRANT AND MATTHEW SALMON
}

\begin{abstract}
Preliminary results of a seven week intensive archaeological survey conducted on Esmeralda Station, Gulf of Carpentaria, are briefly discussed. Sites found include shelters with art and many open scatters of artefacts. A major surprise is the large number of sites containing a high density of grinding surfaces, in particular (food ?) grinding patches.
\end{abstract}

\section{Introduction}

The Gulf of Carpentaria has been relatively neglected in archaeological research despite the knowledge that at the time of European contact during the second half of last century, it supported complex and diverse Aboriginal cultures (e.g. Wright 1988; Roth 1984). During 1991 we became interested in the Gulf and the Croydon region in particular, not only in an attempt to partially fill this archaeological vacuum but most importantly to test a number of propositions detailed below. Following intensive background research, Esmeralda station was perceived as having the best potential in the short term to yield a wide range of archaeological sites (Figure 1). Prior to our investigations, only two concentrations of sites found along the Esmeralda road were already recorded in the state register. The first concentration had one shelter with stencils and another shelter with stencils and engravings. The second cluster had six sites, including shelters with stencils, some of these with surface artefact scatter and one open site with axe grinding grooves associated with an artefact scatter.

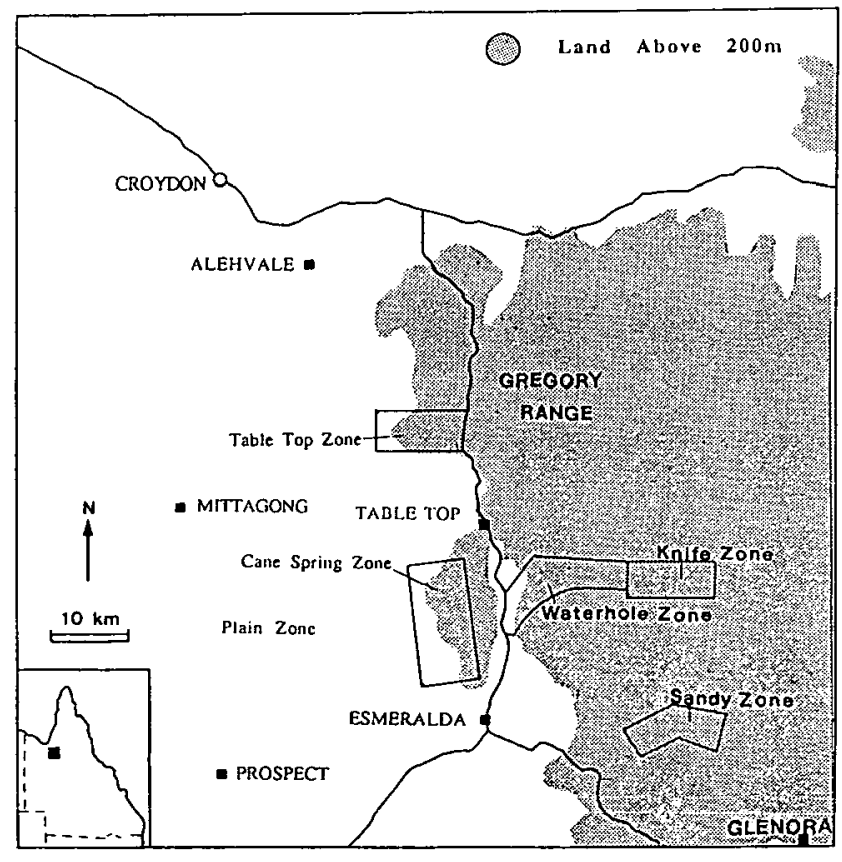

Figure 1: Research Area

\section{Aims}

After consultation with the Croydon Aboriginal community (Waratah Aboriginal Corporation), four priorities were defined for the 1992 fieldwork.

(1) To record some traditional knowledge held by the Takalaka people from Croydon, including ethnobotany, as well as to record some sites of cultural significance to them. These are essentially located at Croydon and on Alehvale and Esmeralda stations (Figure 1).

(2) To undertake a botanical collection for the region given its current poor knowledge (B.Jackes pers.comm. 1992) so as to evaluate the traditional plant resources available.

(3) To assess the nature and range of archaeological sites to be found in four geomorphic units described below, from the flat Gulf of Carpentaria plain to the high country of the Gregory Range.

(4) If sites were found, to evaluate the causes, processes and rate of site deterioration and destruction so as to define priorities for further research before too much archaeological information is lost.

\section{Geomorphic Units}

One remarkable aspect of Esmeralda is that it encompasses four important geomorphic units to be found in the Gulf of Carpentaria. The first is the Gulf plain itself. Starting from Esmeralda homestead, the flat and seemingly endless plain stretches westward for over $250 \mathrm{~km}$ before reaching the sea. The overall poor drainage here is highlighted by its gradient, rising to less than $150 \mathrm{~m}$ above sea level over that distance (or a very low rise of only $60 \mathrm{~cm}$ on average for every kilometre). This is classic bulldust country turning into deep mud in the wet season, a constructional land surface (Perry 1964). It supports an open eucalypt and paperbark woodland, sometimes interrupted by vast expanses of grassland. Despite its overall appearance, the Gulf plain should be perceived as being a vast mosaic of micro-environments rather than as a monotonous unit.

On Esmeralda, the eastern edge of the plain abuts on a sandstone escarpment up to $60 \mathrm{~m}$ in height. This unit, called here the Frontal Escarpment, contains numerous gorges opening westward onto the Gulf Plain. It is the very first secured dry ground to be found from the sea. 
A number of permanent springs are located within it. Many of these gorges have stepped scarp formations and numerous mesas provide spectacular scenery. Overall the unit is subject to severe erosion, it is a destructional land surface (Perry 1964). The vegetation is constantly changing, from grassland to open woodland including dense vine thickets in wet and protected areas.

The third geomorphic unit in the Esmeralda landscape, to the east of the Frontal Escarpment, is the "Plateau", found between 200 and $500 \mathrm{~m}$ asl. Its major feature is the presence of numerous large permanent waterholes. This is rolling hills country, often exposing sandstone or rhyolite outcrops. From a land surface view point it is both constructional (in valley floors and natural depressions) and destructional (slopes and creek beds). It supports a poor and very open vegetation overall, except for dense and mixed plant communities along creek banks and waterholes.

The last broad unit is the Gregory Range Escarpment, found along the eastern margin of the Esmeralda Plateau. Here too the transition is abrupt, with a continuous dissection of deep sandstone gorges and mesas, sometimes rising over $100 \mathrm{~m}$ above the valley floor. The landscape on the Gregory plateau is flat, supporting endless spinifex expanses interspersed by stands of lancewood. Severe erosion occurs throughout the unit. The gorges often have vertical walls with narrow floors supporting a dense vine thicket, particularly where springs and rockholes are found.

\section{Survey Methods}

Methods followed in the field consisted of small parties led by one of us having specific areas to cover for the day and sometimes for a number of days (requiring overnight bivouacs). Botanical collections, under the responsibility of M. Grant (for her Honours thesis), were made on a daily basis by each team and specific areas were intensively collected because of their ethnobotanical potential. Taphonomic observations, under the responsibility of M.Salmon (for his Honours thesis; Salmon 1992), were constantly noted so as to identify areas of greatest site deterioration. Global Positioning Systems (GPS) were used to precisely locate sites (and ourselves ... ) on maps and aerial photos. We estimate that in 1992 we spent 2500 person hours in the field over a seven week period. While we regularly gave progress reports to the Aboriginal and grazier communities, the task of recording traditional knowledge in the study area fell essentially on M.Grant.

There are so many diverse environments on Esmeralda (a property of one million acres) that a sampling strategy had to be followed. Our intention was to have the broadest approach in 1992 so as to gain a preliminary understanding of these as well as to familiarise ourselves with the logistic difficulties and safety procedures to follow. In this general approach, we could gain a preliminary insight on the four major units available to us and, most importantly, a preliminary comprehension on the type, range and content of archaeological sites to be found. As a result, six zones covering the four geomorphic units were selected for 1992 (Figure 1). These are:

(1) Plain Zone (within the Plain Unit). Only brief transects could be carried out given the extreme logistic difficulties.

(2) Cane Spring Zone (within the Frontal Escarpment Unit). This is the most intensively investigated zone.

(3) Table Top Zone (also within the Frontal Escarpment Unit). This was surveyed so as to compare its results with those obtained from Cane Spring zone. It was assumed they would be rather similar.

(4) Watemole Zone (within the Plateau Unit). Surveys were essentially restricted to specific permanent waterholes and along some major water courses.

(5) Sandy Creek Zone (within the Gregory Range Escarpment Unit). Intensive surveys of the gorge system and adjacent valley floors.

(6) Knife Creek Zone (within the Gregory Range Escarpment Unit). A repeat of the Sandy Creek exercise so as to have two comparative samples within the same unit. Here too it was expected that the results would be rather similar to those of Sandy Creek.

In addition to these, a number of surveys on Alehvale station were carried out with members of the Takalaka community. Further, long interviews were conducted with Takalaka elders on the traditional use of Alehvale and on a number of story places and other places of significance. Unfortunately it is not the scope of this paper to discuss the results from Alehvale.

\section{Survey Results}

Following the background research, it was predicted that the surveys would yield different results for each of the units investigated. Overall, 150 archaeological sites were found. Results are presented according to each of the zones surveyed (Table 1). Five sites of cultural significance to the Takalaka people were visited and recorded. Time did not permit to inspect other cultural sites known in the area. These cultural sites are not discussed here.

Plain Zone: because of the nature of the Gulf of Carpentaria plain, with its very high depositional rate within a constructional land surface (Perry 1964) and its periodical catastrophic flooding (Andersen 1983), it was predicted that no or very few archaeological sites would be found. The chance of finding unusual plant communities indicating possible cultural orchards was also taken into consideration. To our surprise, 10 archaeological sites were found despite the limited surveys (Table 1). Nine of these were open scatters of artefacts of various size and density. The remaining site was an enormous concentration of axe grinding grooves (AGG), as well as grinding surfaces (GS) presumably for food processing, all of these associated with an extensive scatter of artefacts.

Cane Spring Zone: found within the Frontal Escarpment Unit, this is the zone which was the most intensively 
Table 1: Results of 1992 Surveys, Esmeralda

\begin{tabular}{|c|c|c|c|c|c|c|c|}
\hline & Plain & Cane & Table Top & Watemole & Sandy & Knife & Total \\
\hline \multicolumn{8}{|l|}{ OPEN SITE } \\
\hline Scatter of artefacts & 9 & 34 & & 2 & 1 & 3 & 49 \\
\hline Quarry & & 1 & & 2 & 1 & 3 & 7 \\
\hline Artefacts, GS & & & . & 3 & 1 & 9 & 13 \\
\hline Artefacts, GS, AGG & 1 & & & 1 & 2 & 1 & 5 \\
\hline GS, AGG & & & & & 7 & & 7 \\
\hline GS & & 1 & & & 9 & 16 & 26 \\
\hline AGG & & & & & 7 & & 7 \\
\hline \multicolumn{8}{|l|}{ ROCK SHELTER } \\
\hline Art only & & 15 & & 1 & 1 & 4 & 21 \\
\hline Art, artefacts & & 5 & & 1 & 1 & 1 & 8 \\
\hline Art, artefacts, GS & & 1 & & & & & 1 \\
\hline Art, GS & & & & & 1 & & 1 \\
\hline GS & & & & & & 1 & 1 \\
\hline Artefacts & & 4 & & & & & 4 \\
\hline TOTAL & 10 & 61 & 0 & 10 & 3.1 & 38 & 150 \\
\hline
\end{tabular}

GS: Grinding Surface. AGG: Axe Grinding Groove

surveyed. Perhaps as a result of this, it yielded more archaeological sites than any other zone. A total of 61 sites were found, evenly distributed between rock shelter and open sites (Table 1). For the latter, the majority of sites were scatters of artefacts ( 34 or $94 \%$ ) of varying size and density. One quarry was also located as well as one site exclusively containing grinding surfaces. A total of 21 rock shelters containing rock art were discovered (or $84 \%$ of shelter sites). The number of images found at these varied from one to more than 170. Six of these sites had also a surface scatter of artefacts, with one having in addition a number of grinding surfaces. Finally, four shelters found contained only a surface scatter of artefacts. While there is abundance of rock shelters in this zone, many of which being highly suitable for occupation, very few have left evidence of prehistoric (and historic) activities.

Table Top Zone: to confirm the nature and distribution of the sites found in Cane Spring Zone, it was decided to carry out another survey within the same broader geomorphic unit. Table Top Zone was the subject of an intensive survey as well. To our great surprise and disappointment, not a single archaeological site was found despite the presence of numerous shelters and "attractive" open spaces. It should be noted that it is within this zone that a concentration of two art sites already in the state register is located.

Waterhole Zone: despite the small sample investigated, ten sites were found in this zone during the 1992 surveys (within the Plateau Unit; Table 1). Six of these were scatters of artefact, four of which had also a number of grinding surfaces with one site having in addition axe grinding grooves. Two rock shelters containing rock art were also found, one of which had a dense surface scatter of artefacts as well. With further surveys, there is no doubt that this zone should yield many more sites.

Sandy Creek Zone: this is the first of two zones investigated at the base of the Gregory Range. A wide range of sites were found, 20 out of the 31 (65\%) containing grinding surfaces (Table 1). Half of the sites found had axe grinding grooves. It should be noted that despite the inspection of "hundreds" of rock shelters, only three contained archaeological material.

Knife Creek Zone: to see if the results of Sandy Creek zone could be extrapolated to the remainder of the base of the Gregory Range within Esmeralda station, it was 
decided to survey the headwaters of Knife Creek. While these are not exactly similar, there seems to be some parallel between the two zones (Table 1). Here too the dominant site is the one with grinding surfaces, found at 27 of the 38 sites located $(71 \%)$. The notable difference is that only one site had axe grinding grooves (or $3 \%$ as against $52 \%$ for Sandy Creek Zone).

Botany/Ethnobotany: a total of 543 botanical samples were collected and processed in the field. Of these, at least 232 different species have so far been identified by Besty Jackes (Botany, JCU). While little can be said at this early stage, it is clear that the collection will add to our botanical knowledge for the region. Work is currently in progress to assess the ethnobotanical potential of this collection. The final results will be presented elsewhere. It should be noted that it is not only the botany of the region that is poorly known, the same applies to its zoology (Ingram and Raven 1991).

Alehvale Station: it is within this station that a number of sites significant to the Takalaka people were inspected, in the course of which a number of archaeological sites were found. A number of ethnobotanical surveys with members of the Takalaka community were also conducted. All results from Alehvale will be presented elsewhere and are not discussed further.

\section{Discussion}

The results of these 1992 surveys on Esmeralda were extremely satisfactory if considering the fact that so little was known for this part of the Gulf of Carpentaria. Archaeological sites are found in all geomorphic units. Despite the overall limited surveys, a wide range of sites was found in a variety of microenvironments. In the field, the question of "where are there no sites?" was eventually asked. A number of preliminary trends are emerging.

The subjective belief that no archaeological sites are to be found in the Gulf of Carpentaria Plain unit appears to be grossly misleading. It is true that it is a difficult environment to work in and that natural site formation processes are particularly destructive, but it now appears that archaeological sites not only exist in the unit but that some of these are still well preserved. Further, some anomalies noted in the plant distribution at specific locations require further investigation. The possibility of finding cultural orchards cannot be discarded.

Despite the presence of a large number of rock shelters highly suitable for a range of human activities within the Frontal and Gregory Range escarpments, very few of these attest to their use by humans. Only 36 of the 150 archaeological sites found are rock shelters $(24 \%)$. Among these, only $13(36 \%)$ have stone artefact remains that could indicate human occupation. This preliminary evidence strongly suggests that shelters overall were avoided but when in use it was predominantly for specific activities related to rock painting (86\%). The use of rock shelters in the past and the present is certainly a complex issue (Nicholson and Cane 1991; Gorecki 1988, 1991).
Another surprising result is the very high number of sites with grinding surfaces discovered throughout the areas surveyed. Overall, 54 such sites were found (36\%) in a region where previously none was reported. At this early stage it is assumed that these features were used to process food.

A major point emerging from these 1992 surveys is that it is too premature to present a predictive model for site location and content. The total absence of sites at Table Top Zone for instance, that we are at a loss to explain, is a clear warning for this

Finally, our taphonomic observations on site disturbance and destruction point towards a rapid and substantial loss of archaeological sites. The Table Top results may be an indication of this. A number of field priorities are currently being defined for future surveys before much archaeological information is permanently lost.

\section{Conclusion}

It is clear that more work is required, not only on Esmeralda but also on properties further south, before one can gain a clear understanding of the surface archaeology of the region. More intensive surveys will be conducted during 1993, perhaps followed by soundings at selected sites during 1994.

The ultimate aims are not only to provide the Takalaka community with concrete data on their past heritage, but to better understand the overall prehistory of the Gulf of Carpentaria, an important and vast region of Queensland. Eventually, one should be in a position to see what is the position of the Croydon region in relation to the prehistory of northwest Queensland. That is, how it relates to its nearest known archaeological regions: Lawn Hill some $400 \mathrm{~km}$ to the west (Hiscock 1988), Hughenden some $350 \mathrm{~km}$ to the southeast (Morwood 1990) and Chillagoe some $300 \mathrm{~km}$ to the northeast (Campbell 1984).

\section{Acknowledgments}

We wish to thank the Waratah Aboriginal Corporation, the Tunney families and Shane Smith for allowing us to carry out this research on Esmeralda and Alehvale stations. Full support and assistance was also received from the entire Croydon community, with a special mention to the Douglas family. A permit to undertake archaeological surveys was granted by the Queensland Department of Environment and Heritage to Gorecki and Salmon for Esmeralda (16P/RES/92) and to Grant for Alehvale (2P/RES/92). This research was supported by a Minor ARC Grant (ARC 4480).

The magnitude and success of the field surveys would not have been possible without the cheerful assistance of many: S.Arlidge, P.Dempsey, L. Gleich, J.Innes, J.Lahn, A.Lovell, C.MacDougall, L.McLean, A.Morgan, B.New, R.Petersen, A.Plant, T.Richardson, P.Risojevic, G.Smith, P.Spencer, M.Suzuki and K.Tanabe (all from JCU), P.Perret (France), H. and J.P.Siorat (New Caledonia), and J.C.Galipaud and P.Kolmas (Vanuatu). 


\section{References Cited}

Andersen, J. 1983 Bagmen Millionaires: Life and people in outback Queensland. Melbourne: Lloyd ONeill.

Campbell, J.B. 1984 Extending the archaeological frontier: a review of work on the prehistory of North Queensland. Queensland A rchaeological Research 1: 173-184.

Gorecki, P.P. 1988 Hunters and shelters - the need for ethnoarchaeological data. In B. Meehan and R. Jones (eds) A rchaeology with Ethnography - an A ustralian Perspective, pp.159-170. Canberra: Department of Prehistory, Research School of Pacific Studies, The Australian National University.

Gorecki, P.P. 1991 Horticulturalists as hunter-gatherers: rock shelter usage in Papua New Guinea. In C.S. Gamble and W.A. Boismier (eds) Ethnoarchaeological Approaches to Mobile Campsites, pp.237-262. International Monographs in Prehistory, Ethnoarchaeological Series 1. Ann Arbor, Michigan.

Hiscock, P. 1988 Prehistoric settlement patterns and artefact manufacture at Lawn Hill, northwest Queensland. Unpublished Ph.D. thesis, University of Queensland.

Ingram, G.J. and Raven, R.J. (eds) 1991 An Atlas of Queensland's Frogs, Reptiles, Birds and Mammals. Brisbane: Board of Trustees, Queensland Museum.

Morwood, M.J. 1990 The prehistory of Aboriginal landuse on the upper Flinders river, North Queensland highlands. Queensland Archaeological Research 7:3-56.
Nicholson, A. and Cane, S. 1991. Desert Camps: analysis of Australian Aboriginal proto-historic campsites. In C.S. Gamble and W.A. Boismier (eds) Ethnoarchaeological Approaches to Mobile Campsites, pp.263-354. International Monographs in Prehistory, Ethnoarchaeological Series 1. Ann Arbor, Michigan.

Perry, R.A. (ed) 1964 General Report on Lands of the Leichhardt-Gilbert A rea, Queensland, 1953-4. Land Research Series No 11. Melbourne: Commonwealth Scientific and Industrial Research Organisation.

Roth, W.E. 1984 (1897). Ethnological studies among the North-west-central Queensland A borigines. Carlisle: Hesperian Press.

Salmon, M. 1992 Esmeralda: a consideration of natural site formation processes. Unpublished B.A.(Hons) thesis, James Cook University.

Wright, B. 1988 Between Two Rivers: The Aborigines of the Leichhardt Gilbert Region of North West Queensland. Cultural Resource Management Monograph Series No. 7. Brisbane: Department of Community Services.

Paul Gorecki, Miranda Grant and Matthew Salmon Dept. of Anthropology and Archaeology James Cook University Townsville Queensland 4811 